\title{
Chatbots e Alunos do Ensino Médio: É possível estabelecer uma conexão?
}

\begin{abstract}
Ana Cristina Moraes da Costa ${ }^{1,2}$, Alice Alves Franco ${ }^{2}$, Ana Cláudia Cabral, Carlos Alexandre Chacon Caetano ${ }^{1}$, Felipe de Jesus Araújo da Conceição ${ }^{1}$, Ricardo Jullian da Silva Graça ${ }^{1}$, Tereza Cristina Moraes do Nascimento ${ }^{2}$
\end{abstract}

\author{
${ }^{1}$ LIpE - Escola Politécnica - Universidade Federal do Rio de Janeiro \\ Caixa Postal 68.533 - 21.941-972 - Rio de Janeiro - RJ - Brasil \\ ${ }^{2}$ Secretaria de Estado de Educação do Rio de Janeiro - SEEDUC-RJ \\ ${ }^{3}$ Baruk - Tecnologias \& Chatbots \\ \{anacristina@poli.ufrj.br, alicepsifrancoegmail.com, \\ anaclaudia06@gmail.com, carlosalexchacegmail.com, \\ lipeconceicaol3@gmail.com, jullianepoli.ufrj.br, \\ terezacmn41@gmail.com\}
}

\begin{abstract}
This work presents a case study from an introduction course to the logic of programming and another one of Artificial Intelligence that were offered to students of the High School in a public school of periphery, from Secretary of Education of the State of Rio de Janeiro, and its developments. The active methodologies are proposed to the teaching of programming logic and artificial intelligence using chatbot. Thus, students were able to develop skills to solve problems within the school community using artificial intelligence knowledge, developing chatbot.
\end{abstract}

Resumo. O presente trabalho apresenta um estudo de caso, a partir de um curso de introdução à lógica de programação e outro de Inteligência Artificial que foram oferecidos à alunos do Ensino Médio numa escola pública de periferia, da Rede Estadual de Educação do Rio de Janeiro, e seus desdobramentos. As metodologias ativas são propostas que cabem muito bem ao ensino de lógica de programação e inteligência artificial utilizando chatbot. Assim, os alunos puderam desenvolver habilidades para solucionar problemas dentro da comunidade escolar utilizando conhecimentos oriundos da Inteligência artificial, desenvolvendo chatbot.

\section{Introdução}

Há décadas, a Inteligência Artificial (IA) vem desenvolvendo pesquisas e programas de software visando dar ao computador a capacidade de conversar com o homem de forma natural. Esses programas são chamados chatterbots ou chatbots e podem ser construídos para os mais diversos fins [Castanho 2002]. Exemplos de chatbots podem ser encontrados nas áreas de saúde, entretenimento, negócios e educação. Kuyven et al (2018) realizaram uma revisão sistemática da literatura acerca da aplicação dos chatbots para fins educacionais em bases de dados nacionais e internacionais. Entretanto, por meio da 
VIII Congresso Brasileiro de Informática na Educação (CBIE 2019)

Anais do XXV Workshop de Informática na Escola (WIE 2019)

análise, constatou-se que a maior parcela dos chatbots se encontrava na área de conhecimento da Ciência da Computação e que era destinada para o nível de ensino superior.

A verdade é que o mundo vem mudando de forma extremamente rápida. Apesar de vivermos na era digital e de fazer uso de diversas tecnologias em nosso cotidiano, esse mundo não está integrado à escola. Há necessidade de uma outra proposta de escola, muito mais leve, aberta, flexível, centrada no aluno com atividades significativas, metodologias ativas e intenso uso das tecnologias digitais [Moran 2017].

As metodologias ativas num mundo conectado e digital se expressam por muitas possíveis combinações, trazendo inúmeras possibilidades de arranjos, itinerários e atividades [Schlemmer 2013; Schlemmer 2014]. Elas são importantes na valorização do protagonismo do aluno, estimulando seu envolvimento direto, participativo e reflexivo em todas as etapas do processo educativo. Exigem o contato com entornos reais, com problemas concretos da comunidade, não só para conhecê-los, mas para procurar contribuir com soluções reais. Nesse processo, os alunos lidam com questões interdisciplinares, tomam decisões e agem sozinhos e em equipe [Moran 2017], sob a mediação do professor.

Assim, alguns questionamentos são necessários. Como a escola pode se tornar interessante para o aluno num mundo conectado e em constante transformação? O que é necessário trazer do dinamismo das transformações digitais para o ambiente escolar? Será que o aluno da escola pública de periferia, especificamente do Ensino Médio (EM), tem interesse em fazer um curso extraclasse de introdução à IA? Será que consegue desenvolver ferramentas a partir da IA (utilizando chatbots) para tentar resolver um problema da comunidade escolar?

O presente trabalho apresenta um estudo de caso a partir de um curso de introdução à lógica de programação e de IA que foram oferecidos à alunos do EM numa escola pública de periferia, da Rede Estadual de Educação do Rio de Janeiro, e seus desdobramentos. O projeto foi realizado com a parceria do Laboratório de Informática para Educação, da Universidade Federal do Rio de Janeiro (LIpE/UFRJ) e da empresa Baruk - Tecnologias \& Chatbots.

\section{Inteligência Artificial e a relação com a educação}

Os chatbots são programas de computador que, de certa forma, orquestram de maneira simulada comportamentos humanos no ato comunicacional. Eles são frutos da fusão entre a IA e técnicas de processamento de linguagem natural (PLN).

Segundo Gartner (2017), os chatbots estão sendo desenvolvidos para desempenhar uma série de funções voltadas à comunicação e interação entre usuário e máquina para fim de auxiliar e facilitar o fluxo de informação entre eles. No campo educacional, o uso dos chatbots vem se expandindo. Há robôs ou aplicativos que escrevem histórias, que desenham novos edifícios, que se adaptam a cada aluno e lhes ensinam línguas [Moran 2017].

Kuyven et al. (2018), já citado anteriormente, apresentaram uma revisão sistemática de literatura sobre o uso de chatbots com objetivos educacionais, no período entre 2000 a 2017. Na busca inicial, 159 publicações foram encontradas. Entretanto, apenas 16 foram selecionadas após a aplicação dos critérios de exclusão e inclusão. A 
VIII Congresso Brasileiro de Informática na Educação (CBIE 2019)

Anais do XXV Workshop de Informática na Escola (WIE 2019)

maior parcela (7-43,7\%) correspondeu aos agentes desenvolvidos para o ensino superior. Em segundo lugar (3-18,8\%), estavam os chatbots aplicados no EM. Nos níveis do ensino fundamental, pós-graduação e adaptável a vários níveis, identificou-se dois artigos $(12,5 \%)$ em cada. Constatou-se, assim, que o nível educacional mais presente nas pesquisas foi o do ensino superior, possivelmente justificado pela maior adoção de ferramentas tecnológicas neste nível educacional.

\section{Chatbot desenvolvido por alunos do EM numa escola de periferia}

Esse trabalho foi desenvolvido no Centro Integrado de Educação Pública, CIEP-165 Brigadeiro Sérgio Carvalho, da Rede Estadual do Rio de Janeiro, localizado na zona oeste do Município do Rio de Janeiro.

Em 2016, três professoras do CIEP-165 participaram do curso de formação continuada "Tecnologia \& Educação", oferecido pelo LIpE/UFRJ. Essa formação e parceria possibilitou a revitalização da sala de informática do CIEP e a implementação de cursos relacionados à lógica de programação para a comunidade escolar. Em 2017, formou-se a primeira turma de alunos no curso de introdução à lógica de programação de computadores utilizando a linguagem Python, conforme descrito no trabalho de Costa et al. (2017).

Em 2018, ampliou-se a parceria entre Universidade x escola com a empresa Baruk - Tecnologias \& Chatbots, permitindo que quinze (15) alunos do CIEP 165, além do curso de introdução à lógica de programação, participassem do curso de introdução à IA. A carga horária de cada um deles era de vinte (20) horas.

O trabalho de final do curso de IA foi baseado no conteúdo abordado a partir da platafoma Manychat e na criação de chatbots. É importante ressaltar que em 2016, o Facebook inaugurou a associação entre Messenger e chatbots. O Manychat é uma das plataformas especializadas em bot que oferece a maioria de seus recursos principais de forma gratuita. Ela fornece uma interface simples e de fácil compreensão para a criação de chatbots [Oliveira et. al, 2018].

Como alguns alunos concluintes tiveram a oportunidade de estagiar na secretaria do CIEP, eles puderam observar que existiam ruídos de comunicação entre a secretaria e a comunidade escolar. Muitas pessoas se dirigiam até lá para esclarecer dúvidas simples. Essa situação causava grandes filas no momento de atendimento escolar. Com o intuito de amenizar o problema, os alunos criaram um chatbot e implementaram na página do Facebook do CIEP 165. Ele foi criado seguindo um sistema simples de perguntas respostas que eram frequentes no contexto da secretaria escolar.

\section{Alguns resultados e discussão}

A figura 1, mostra a interface da plataforma Manychat bem como o processo de criação de chatbot da página do Facebook do CIEP 165. Como observado na imagem, o chatbot se baseia em um sistema de botão em que o usuário interage com o bot. Essa plataforma possui um esquema de fácil compreensão, o que possibilita sua utilização com alunos dos mais diversos segmentos escolares. 
VIII Congresso Brasileiro de Informática na Educação (CBIE 2019)

Anais do XXV Workshop de Informática na Escola (WIE 2019)

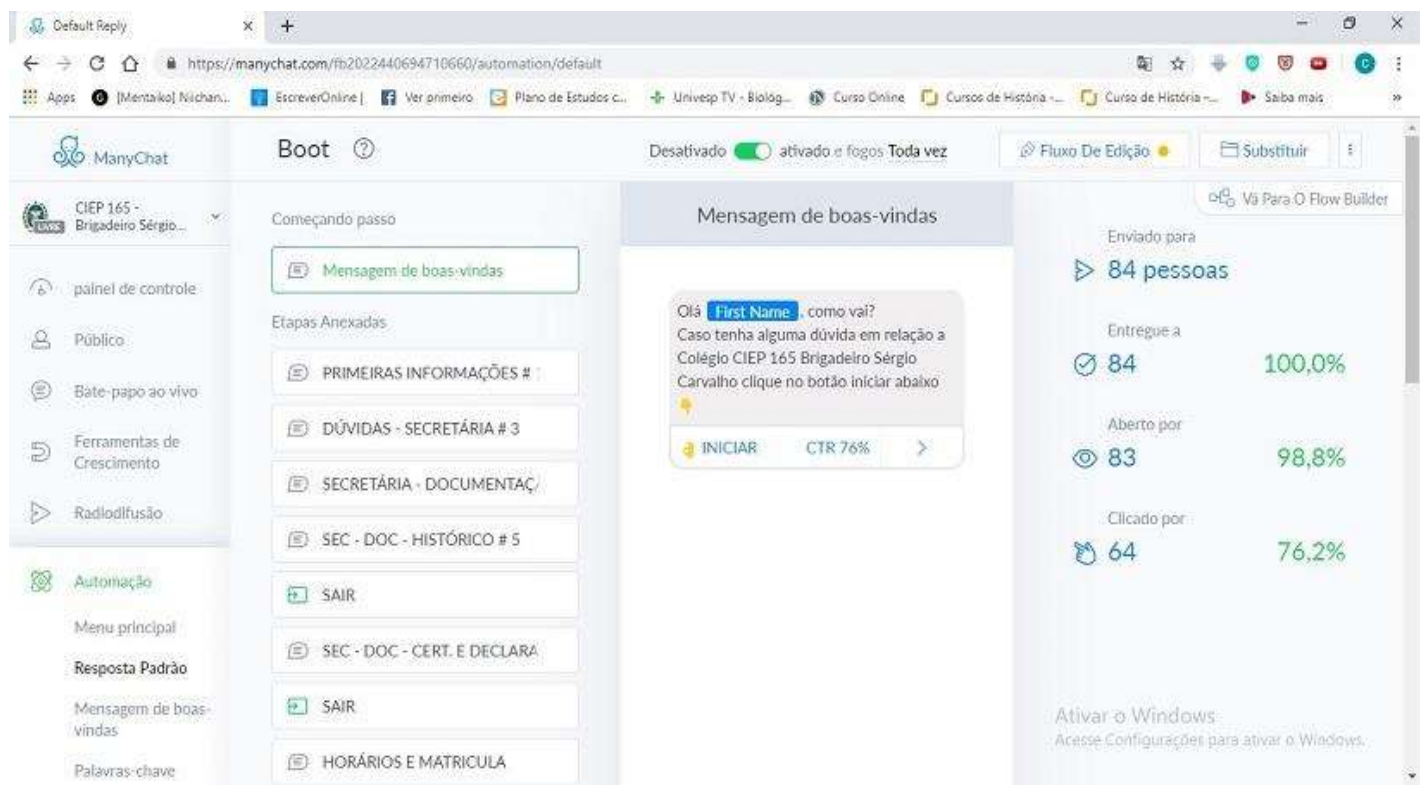

Figura 1. Interface da plataforma Manychat de criação do chatbot

Através dos dados, verifica-se um acesso menor do que o esperado. Isso se deve, principalmente, ao baixo índice de divulgação da página no Facebook do CIEP 165. Ela possui uma taxa de intervalo das publicações que varia entre 11 e 12 dias (dados retirados da plataforma Facebook). Essa taxa faz com que o alcance das publicações dessa página não evolua e, consequentemente, diminua/paralise a sua popularidade.

O Facebook oferece uma série de funcionalidades que, em sua grande maioria, possibilitam a interação entre esses usuários. Ele proporciona um momento de lazer em função de suas diversas ferramentas como chat, feed, timeline, entre outras [Aquino e Brito 2012]. A página do CIEP 165 criada nessa plataforma possui uma função distinta do que se espera dentro do Facebook. Enquanto a plataforma gira em torno dos aspectos de diversão e distração, ela funciona como mecanismo meramente informativo, ou seja, tem como função simplesmente informar a comunidade escolar. Assim, o chatbot da página acaba por não ser utilizado.

Esse projeto ainda está em fase de desenvolvimento. Sua criação visa atenuar ou, de certa forma, solucionar os problemas referentes ao chatbot desenvolvido pelos alunos. A ideia inicial é implementar esse chatbot à página web da escola, a partir da plataforma Chatfuel que além de permitir a interação entre chatbot e Facebook como o Manychat, possibilita a utilização desses chatbots em páginas Web. Ele visa criar um ambiente baseado na informatividade e interatividade em que o chatbot possa ser utilizado de uma maneira mais eficiente.

\section{Conclusão}

As metodologias utilizadas nos cursos de introdução à lógica de programação e de IA possibilitaram aos alunos serem autônomos e reflexivos. Eles puderam problematizar a realidade, a partir de desafios, suscitando um trabalho em equipe, inovador, onde o "instrutor" foi apenas um mediador, um facilitador e ativador de todo processo de ensino e aprendizagem. 
VIII Congresso Brasileiro de Informática na Educação (CBIE 2019)

Anais do XXV Workshop de Informática na Escola (WIE 2019)

É importante destacar o fato do chatbot ter sido desenvolvido pelos próprios alunos, dentro de uma escola pública de periferia, onde foi possível "construir" um ambiente propício para produção de conhecimento a partir da prática e da coletividade. Embora os cursos tenham sido oferecidos como atividade extraclasse (no contraturno), fora do espaço da sala de aula, o interesse dos alunos foi o grande diferencial. O modelo dos cursos pode ser replicado com os mais variados contextos, com um caráter interdisciplinar e até transdisciplinar.

Assim, as tecnologias digitais ganham uma importância estratégica na atualidade, ampliam as possibilidades de pesquisa, autoria, compartilhamento, publicação, multiplicação de espaços e de tempo. Elas favorecem o aprendizado interdisciplinar e multifacetado do aluno, possibilitando que faça conexões com o mundo ao seu redor. Nesse aspecto, a educação, pouco a pouco, ganhará cada vez mais o sentido de pluralidade e modernidade que, de uma forma geral, poderá reformular o processo de construção do conhecimento do estudante.

\section{Referências}

Aquino, A., Brito, A. (2012) "Estudo da viabilidade do uso do Facebook para educação". In: Workshop sobre Educação em Informática, Curitiba.

Castanho, C. L. O. (2002). "A avaliação do uso de chatterbots no ensino através de uma ferramenta de autoria". Dissertação de mestrado em Ciência da Computação, UFSC, Santa Catarina.

Costa, A. C. M., Graça, R. J., Franco, A. A. et al. (2017). "Python: Será que é possível numa Escola Pública de Ensino Médio". In: Anais do XXI Workshop de Informática na Escola (WIE). 255- 264. https://doi.org/10.5753/cbie.wie.2017.255

Gartner, Inc. (NYSE: IT). http://www.gartner.com/newsroom/id/3412017

Kuyven, N. L., Antunes, C. A., e Vanzin, V. J. B. (2018). "Chatbots na educação: uma Revisão Sistemática da Literatura". Novas Tecnologias na Educação, 16 (1), 110. https://doi.org/10.22456/1679-1916.86019

Moran, J. (2017). "Como transformar nossas escolas: Novas formas de ensinar a alunos sempre conectados". Publicado no livro Educação 3.0: Novas perspectivas para o Ensino. CARVALHO, M. (Org). Porto Alegre, Sinepe/RS/Unisinos.

Oliveira, M. A. F., Melo, J. N. B. e Lima, J. V. (2018). "Sala de aula invertida com apoio de um chatbot: uma alternativa de ensino para potencializar a aprendizagem da matemática”. Sánchez, J. Editor. Nuevas Ideas en Informática Educativa: Santiago de Chile, 14, 499-503.

Schlemmer, E. (2013). "Gamificação em espaços de convivência híbridos e multimodais: uma experiência no ensino superior (cognição em jogos digitais)". Projeto de Pesquisa. Edital MCTI/CNPQ/MEC/CAPES nº 43/2013. São Leopoldo.

Schlemmer, E. (2014). "Gamificação em espaços de convivência híbridos e multimodais: design e cognição em discussão". Revista da FAEEBA - Educação e $\begin{array}{llll}\text { Contemporaneidade, } & \text { Salvador, } & 23 & \text { (42), }\end{array}$ file://C:/Users/Recep\%C3\%A7\%C3\%A30\%202/Downloads/1029-2436-1-SM.pdf 